\title{
Computational analysis of a dual-port semi-circular patch antenna combined with Koch curve fractals for UWB systems
}

\author{
Arashpreet Sohi ${ }^{1}$ and Amanpreet Rajpal ${ }^{1}$ \\ ${ }^{1}$ Thapar Institute of Engineering and Technology
}

May 5, 2020

\begin{abstract}
In this manuscript, a two-port semi-circular patch antenna with Koch curve fractals is presented as a suitable candidate for portable UWB communication systems. The proposed fractal array is engraved on a $1.57 \mathrm{~mm}$ thick FR- 4 substrate with an overall array size of $30.5 \times 47 \times 1.64 \mathrm{~mm}$. The upper substrate layer consists of two microstrip-line fed semi-circular patches combined with two Koch curve fractals (optimized up to 2nd order of iteration) separated by a distance of $\lambda / 2$. To mitigate the effect of mutual coupling between the radiating elements, the lower substrate layer consists of a reduced ground plane with a funnel-shaped decoupling structure. To achieve a high degree of isolation (S21/S12 [?] -16.8 dB) between the ports of the proposed array, two rectangular and L-shaped slots (mirror images of each other) are etched from the upper surface of the reduced ground. The design and simulation of the proposed antenna array is implemented in CST MWS'18. The optimized fractal array covers the simulated frequency band from 4.395-10.184 GHz with a fractional bandwidth of $79.4 \%$ (at a center frequency of $5.789 \mathrm{GHz}$ ) and provides a peak radiation efficiency of $88.8 \%$ (at $6.2 \mathrm{GHz}$ frequency). The antenna diversity performance is analyzed in terms of envelope correlation coefficient (ECC [?] 0.0021), diversity gain (DG [?] 9.989), mean effective gain (MEG [?] $-3.7 \mathrm{~dB}$ ), channel capacity loss (CCL [?] $0.4 \mathrm{bits} / \mathrm{s} / \mathrm{Hz}$ ) and total active reflection coefficient (TARC [?] -10 dB). The experimentally measured S-parameter results show a good match with the simulated ones.
\end{abstract}

\section{INTRODUCTION}

Over the past few years, the advancement in ultra-wideband (UWB) radio technology has played a significant role in the wireless telecommunication industry to fulfill the escalating needs of large bandwidth with high speed of data transfer at a low cost and low energy consumption [1]. In 2002, the Federal Communication Commission (FCC) has allocated the usage of unlicensed radio spectrum from 3.1-10.6 GHz (with a fractional bandwidth of $109.5 \%$ at $6.85 \mathrm{GHz}$ center frequency) for commercial UWB applications [2]. Apart from the admirable properties of UWB technology, conventional UWB radio systems suffer from the problem of cochannel fading and interference due to multipath wave propagation from the transmitter to the receiver end. To curb the adverse effects of multipath fading, the UWB devices are designed with multiple-input multiple-output (MIMO) wireless technology which multiplies the capacity of radio channel using multiple antennas at transmitter and receiver. Equation (1) shows the linear relationship between the capacity and signal to noise ratio (SNR) of the MIMO antenna system.

$C=B\left[\log _{2} \operatorname{det}\left(I_{\mathrm{Nr}}+\frac{E_{t}}{\sigma_{n}^{2}+N_{t}}\right)\right.$ H. $\left.H^{H}\right](1)$

where $\mathrm{B}, \mathrm{I}_{\mathrm{Nr}}, \mathrm{E}_{\mathrm{t}}, \sigma_{\mathrm{n}}{ }^{2}, \mathrm{~N}_{\mathrm{t}}, \mathrm{H}$ and $\mathrm{H}^{\mathrm{H}}$ is the channel bandwidth, identity matrix, total input power, noise power, number of transmitter antennas, channel matrix and the hermitian transpose of the channel matrix respectively [3]. 
The integration of UWB-MIMO technologies has become an essential part of modern wireless systems to achieve a high data rate (about 1Gbps), superior radio link reliability, broad communication range and little interference in a rich multipath environment [4]. The physical size constraints of the portable and handheld gadgets pose a challenge to the antenna designers to develop small-sized and low-profile MIMO antennas. To meet these specifications, microstrip patch antenna (MPA) is a suitable choice due to its innate benefits of light-weight, simplicity, less cost, mechanically robust and planar/non-planar surface conformity [5]. For modeling compact user equipment, the inter-element spacing in the MIMO configuration is reduced which in turn degrades the array performance due to increased mutual coupling and alters the radiation pattern of actively radiating elements. Therefore, it is favored to incorporate fractal geometries in MPAs to achieve the desired compactness and multiband/wideband operation in a given restricted area due to its inherent self-similar, self-affine and space-filling characteristics [6]. Also, the combination of defected ground structure (DGS) approach with fractal MIMO antennas helps in achieving the desired size reduction, improved operational bandwidth and reduced mutual coupling between the actively radiating patches [7].

In past, researchers have reported many fractal geometries such as Sierpinski gasket [8], Pythagorean tree [9], Hilbert curve [10], Minkowski [11], etc. for designing MIMO antennas with the ultimate goal to achieve miniaturization and multiband/wideband frequency response. All the previously designed fractal MIMO antennas [8-11] had larger dimensions, less port-to-port isolation and were employed for multiband wireless systems. Based on the literature review, the primary objective of this article is to design, simulate and experimentally test a miniaturized fractal MPA array for high bandwidth and good diversity performance to support high data rate portable UWB systems. In this article, a Koch curve fractal (up to $2^{\text {nd }}$ order of iteration) semi-circular antenna array with the DGS technique is proposed. The proposed fractal array is designed on a commercially available FR-4 substrate with relative permittivity $\left(\varepsilon_{\mathrm{r}}\right)$, loss tangent ( $\tan$ $\delta$ ) and height $\left(\mathrm{h}_{\mathrm{t}}\right)$ of 4.4, 0.024 and $1.57 \mathrm{~mm}$ respectively. The designing and simulation of the proposed fractal array is carried out in time domain solver of computer simulation tool microwave studio version 18 (CST MWS V'18) software with open boundary conditions. The proposed fractal MPA array covers the simulated frequency band from 4.395-10.184 GHz (79.4\% fractional bandwidth) with a peak return loss of $-54.5 \mathrm{~dB}$ (at $9.4 \mathrm{GHz}$ frequency) and isolation [?] -16.8 dB. To justify the performance of the proposed fractal array for practical applications, it is fabricated (using photolithography process) and experimentally tested for S-parameters $\left(\mathrm{S}_{11}, \mathrm{~S}_{22}, \mathrm{~S}_{21}, \mathrm{~S}_{12}\right)$ using a vector network analyzer (VNA). The diversity performance parameters are computed using simulated and measured S-parameters which are found to lie within their acceptable limits.

\section{ANTENNA GEOMETRY AND PARAMETRIC ANALYSIS}

Figure $1(\mathrm{a}, \mathrm{b})$ shows the geometry of a dual-port semi-circular MPA array with Koch curve fractals and a minimized ground plane with DGS for MIMO implementation in UWB radio systems. The proposed fractal array is modeled on a low-cost FR-4 substrate $\left(\varepsilon_{\mathrm{r}}=4.4\right.$, tan $\delta=0.024$ and $\left.\mathrm{h}_{\mathrm{t}}=1.57 \mathrm{~mm}\right)$ with the overall array dimensions of $30.5 \times 47 \mathrm{~mm}^{2}$. As shown in Figure 1(a), the upper FR-4 substrate layer consists of two semi-circular radiating patches (copper), each joined with Koch curve fractal (up to $2^{\text {nd }}$ order of iteration) on its upper edge. The separation distance between the fractal radiators is kept as $\lambda / 2(21.2$ $\mathrm{mm})$. The optimized parametric values of the proposed fractal array are mentioned in Table 1 . The semicircular patches are designed for high resonating frequency where the radius of each semi-circle is calculated by Equation $(2,3)$.

$r=\frac{92 \times 10^{9}}{f_{r} \sqrt{\varepsilon_{\mathrm{eff}}}}(2)$

$\varepsilon_{\mathrm{eff}} \approx \frac{\varepsilon_{r}+1}{2}(3)$

where $r, f_{r} \varepsilon_{r}$ and $\varepsilon_{\text {eff }}$ is the radius of the semi-circle, resonating frequency $(\mathrm{GHz})$, the relative permittivity of the FR-4 substrate and effective dielectric constant of FR-4 substrate respectively [12].

The proposed MSA array is fed using two microstrip transmission lines with 50 characteristic impedance $\left(Z_{\mathrm{o}}\right)$. To realize the desirable matching performance between the radiating patch and microstrip line, the 
feedline width (b) is chosen according to the Equation (4,5) [5].

$$
Z_{O}=\frac{120 \pi}{\sqrt{\varepsilon_{\text {eff }}}\left[\frac{b}{h_{t}}+1.393+0.667 \ln \left(\frac{b}{h_{t}}+1.444\right)\right]}, \text { for } \frac{b}{h_{t}}>1(4) \varepsilon_{\mathrm{eff}}=\frac{\left(\varepsilon_{r}+1\right)}{2}+\frac{\left(\varepsilon_{r}-1\right)}{2}\left(1+\frac{12 h_{t}}{b}\right)^{-1 / 2}(5)
$$

A stub is added at the bottom of the feedline to achieve a wideband response with an improved impedance matching characteristic. The length of the stub is calculated using Equation 6 [4].

$v=\frac{c}{2 f_{r} \sqrt{\varepsilon_{\text {eff }}}}(6)$

The recursive procedure followed to reach the $2^{\text {nd }}$ order of iteration of the Koch curve fractal is shown in Figure 1 (c). To construct the Koch curve fractal, initially, a straight line of length ' 1 ' is considered $\left(0^{\text {th }}\right.$ order of iteration). The length ' 1 ' is further cut into three equal segments (each of length ' $1 / 3$ ') where the central segment is replaced by the two other segments of an equilateral triangle (each with length ' $1 / 3$ ') resulting in the $1^{\text {st }}$ order of iteration. This process is iterated recursively to form the higher order of iterations. The self-similar repetitions of the proposed Koch curve fractal can be generated by iterated function system (IFS) approach, defined by generalized matrix Equation (7) using the set of affine linear transformations 'W'.

$W$

$\left[\begin{array}{l}x \\ y\end{array}\right]=$

$\left[\begin{array}{ll}a & a m p ; b \\ c & a m p ; d\end{array}\right]$

$\left[\begin{array}{l}x \\ y\end{array}\right]+$

$\left[\begin{array}{l}e \\ f\end{array}\right](7)$

where the variables 'a', 'b', 'c' and 'd' deals with rotation $(\vartheta)$ and scaling (s) operations and variables 'e' and ' $\mathrm{f}$ ' deals with translations.

Using $\mathrm{a}=\cos \vartheta / \mathrm{s}, \mathrm{b}=-\sin \vartheta / \mathrm{s}, \mathrm{c}=\sin \vartheta / \mathrm{s}$ and $\mathrm{d}=\cos \vartheta / \mathrm{s}$ where $\mathrm{s}=1 / 3$ and $\vartheta=60 @$ for two segments of equilateral triangle (one in clockwise, other in anticlockwise direction), the required IFS transformation for Koch curve fractal is calculated by Equations (8-11) [13].

$W_{1}$

$\left[\begin{array}{l}x \\ y\end{array}\right]=$

$\left[\begin{array}{cc}1 / 3 & a m p ; 0 \\ 0 & a m p ; 1 / 3\end{array}\right]$

$\left[\begin{array}{l}x \\ y\end{array}\right]+$

$\left[\begin{array}{l}0 \\ 0\end{array}\right] \varphi \circ \rho \vartheta=0^{\sim}(8)$

$W_{2}$

$\left[\begin{array}{l}x \\ y\end{array}\right]=$

$\left[\begin{array}{cc}1 / 6 & a m p ;-\sqrt{3} / 6 \\ \sqrt{3} / 6 & a m p ; 1 / 6\end{array}\right]$ 


$$
\begin{aligned}
& {\left[\begin{array}{l}
x \\
y
\end{array}\right]+} \\
& {\left[\begin{array}{c}
1 / 3 \\
0
\end{array}\right] \varphi о \rho \vartheta=60^{\sim}(9)} \\
& W_{3} \\
& {\left[\begin{array}{l}
x \\
y
\end{array}\right]=} \\
& {\left[\begin{array}{cc}
1 / 6 & a m p ; \sqrt{3} / 6 \\
-\sqrt{3} / 6 & a m p ; 1 / 6
\end{array}\right]} \\
& {\left[\begin{array}{l}
x \\
y
\end{array}\right]+}
\end{aligned}
$$

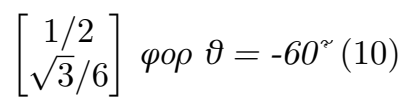

$$
\begin{aligned}
& W_{4} \\
& {\left[\begin{array}{l}
x \\
y
\end{array}\right]=} \\
& {\left[\begin{array}{cc}
1 / 3 & a m p ; 0 \\
0 & a m p ; 1 / 3
\end{array}\right]} \\
& {\left[\begin{array}{l}
x \\
y
\end{array}\right]+} \\
& {\left[\begin{array}{c}
2 / 3 \\
0
\end{array}\right] \text { фор } \vartheta=0^{\curvearrowright}(11)}
\end{aligned}
$$

The self-similarity dimension (D) of the proposed Koch curve fractal is calculated using Equation 12 [6]. In the proposed fractal configuration, four new non-overlapping copies $(\mathrm{N})$ are generated with the scaling factor (s) of $1 / 3$, resulting in a fractal dimension (D) of 1.262 .

$D=\frac{\log (N)}{\log (1 / s)}$

As shown in Figure 1 (b), the lower FR-4 substrate layer consists of a reduced ground with DGS. A funnelshaped decoupling structure extends vertically (at an angle 90@) from the reduced ground plane. It obstructs the steady flow of current between the two radiating patches and hence minimizes the effect of cross-coupling. To further improve the isolation performance, two rectangular (each with dimensions $5 \times 2.5$ ) and L-shaped $(11.6 \times 0.5)$ slots, each with a length of $\lambda_{\mathrm{g}} / 2$ (where $\lambda_{\mathrm{g}}$ is the guided wavelength), is etched from the upper edge of the reduced ground. Figure 2 and Figure 4 show the geometrical variations in the patch and ground plane configuration of the proposed fractal array respectively for designing the final optimized geometry. The corresponding improvement in impedance bandwidth $\left(\mathrm{S}_{11} / \mathrm{S}_{22}\right)$ and isolation $\left(\mathrm{S}_{21} / \mathrm{S}_{12}\right)$ performance for variations in patch and ground plane geometries is depicted in Figure 3 and Figure 5 respectively. 


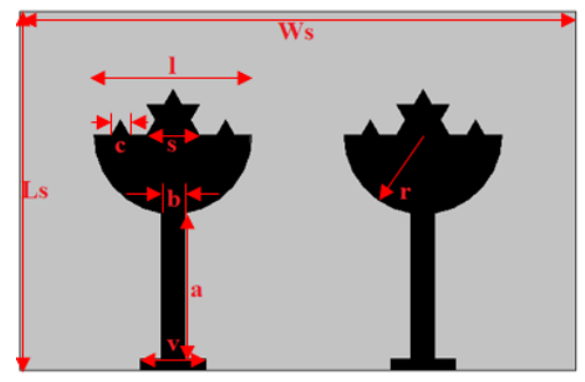

(a)

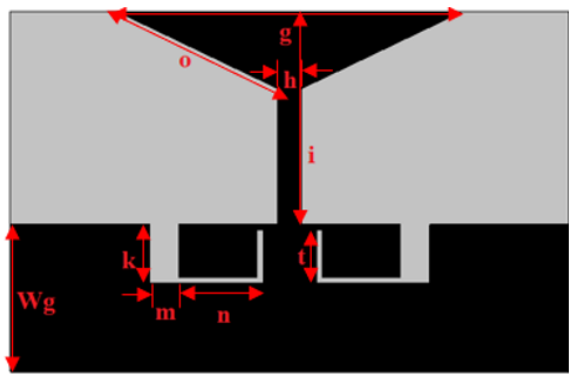

(b)

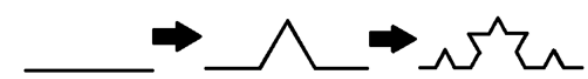

(c)

Figure 1 (a) Microstrip line fed Koch curve fractal radiators (b) Reduced ground with DGS (c) Design procedure for construction of the Koch curve fractal up to $2^{\text {nd }}$ order of iteration

Table 1 Parametric values of the proposed fractal array

\begin{tabular}{llllllllll}
\hline Parameter & $\mathrm{Ls}$ & $\mathrm{Ws}$ & $\mathrm{a}$ & $\mathrm{b}$ & $\mathrm{c}$ & $\mathrm{v}$ & $\mathrm{s}$ & $\mathrm{l}$ & $\mathrm{r}$ \\
\hline Dimensions & 30.5 & 47 & 12.3 & 2.4 & 1.489 & 5.5 & 4.466 & 13.4 & 6.7 \\
Parameter & $\mathrm{Wg}$ & $\mathrm{m}$ & $\mathrm{n}$ & $\mathrm{o}$ & $\mathrm{g}$ & $\mathrm{h}$ & $\mathrm{i}$ & $\mathrm{k}$ & $\mathrm{t}$ \\
Dimensions & 12.5 & 2.5 & 7.11 & 16 & 29.22 & 2 & 18 & 5 & 4.5 \\
\hline
\end{tabular}

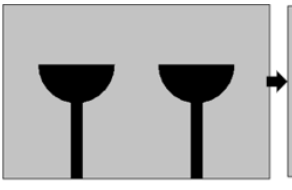

(a)

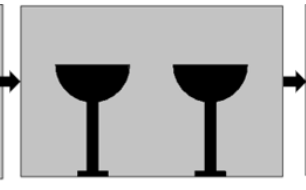

(b)

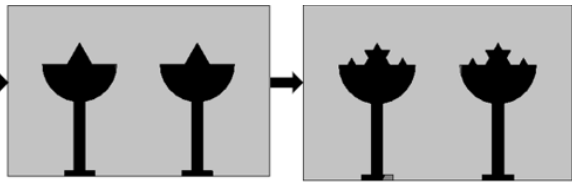

(c)

(d)

Figure 2 Intermediate design steps for the construction of final optimized fractal radiators

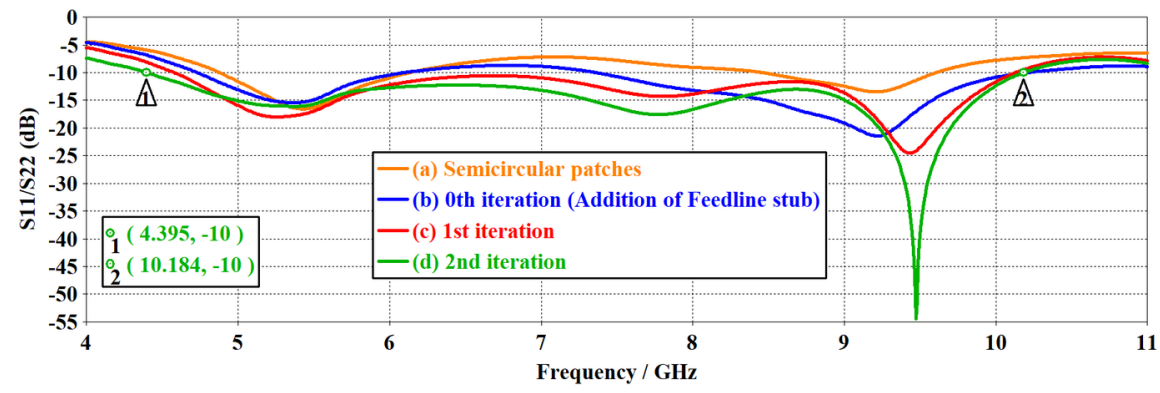

Figure 3 Comparison of $\mathrm{S}_{11} / \mathrm{S}_{22}(\mathrm{~dB})$ characteristics for geometrical variations in the patch 


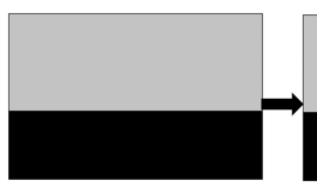

(a)

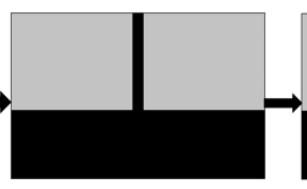

(b)

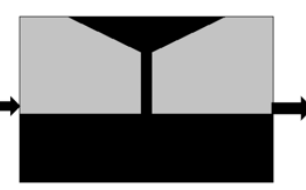

(c)

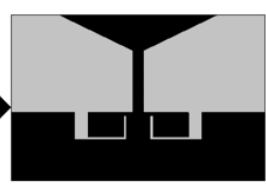

(d)

Figure 4 Geometrical variations in the ground plane geometry for isolation enhancement

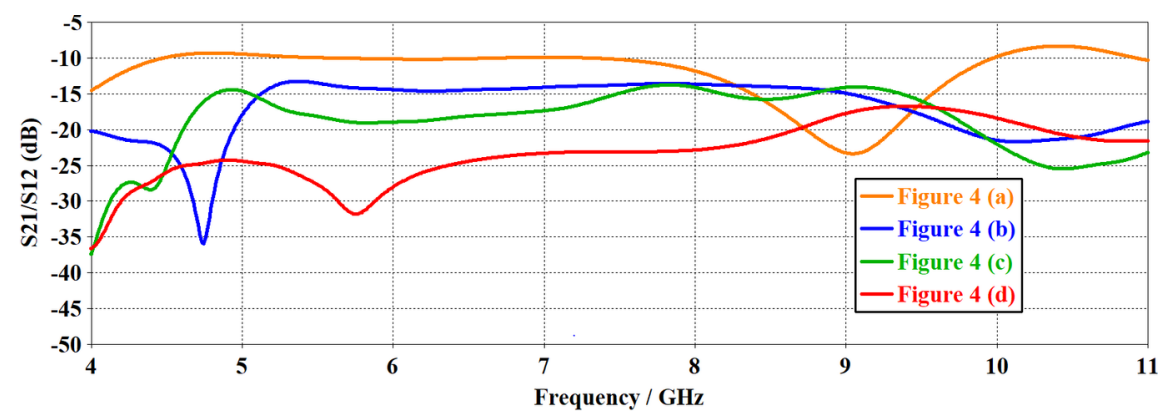

Figure 5 Comparison of $\mathrm{S}_{21} / \mathrm{S}_{12}(\mathrm{~dB})$ characteristics for variations in ground plane geometry

\section{SIMULATED AND MEASURED RESULTS}

To validate the antenna performance in a real practical scenario, the proposed fractal array is fabricated using a photolithography process. The fabricated prototype of the proposed fractal array is tested for S-parameters $\left(\mathrm{S}_{11}, \mathrm{~S}_{22}, \mathrm{~S}_{21}, \mathrm{~S}_{12}\right)$ values using VNA E 5063A (100 KHz-18GHz) under normal laboratory conditions. Figure $6(\mathrm{a}, \mathrm{b})$ shows the snapshot of the front and back view of the fabricated fractal array respectively. To energize the fractal patches, a 50 female subminiature version A (SMA) connector (frequency range up to $18 \mathrm{GHz}$ ) is soldered at the termination of each feedline. Figure 6 (c) shows the snapshot during the measuring of the reflection coefficient on VNA.

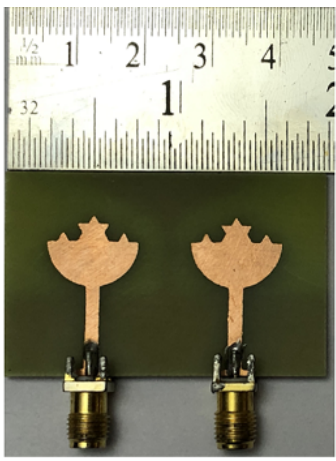

(a)

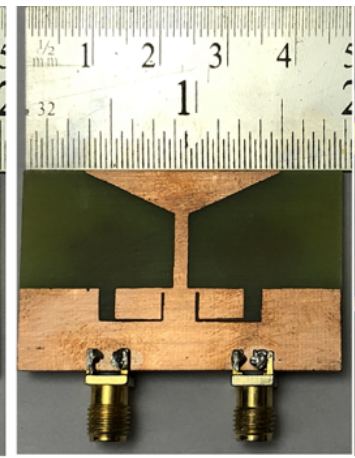

(b)

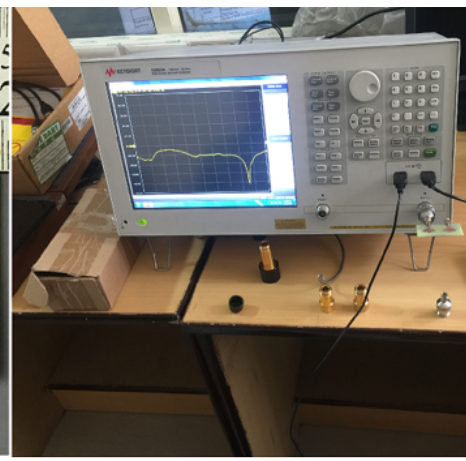

(c)

Figure 6 Snapshots of the fabricated fractal array showing (a) Fractal radiators (b) Ground view (c) Testing of reflection coefficient on VNA

\section{RETURN LOSS $\left(\mathrm{S}_{11} / \mathrm{S}_{22}\right.$ (DB)) CHARACTERISTICS AND VOLTAGE STANDING WAVE RATIO (VSWR)}

Return loss is used to estimate the power absorbed by the antenna from the transmission line. VSWR is defined as the ratio of peak voltage to the minimum voltage in the standing wave pattern that sets up in 
the transmission line due to impedance mismatches. The value of VSWR should lie between 1 and 2 for the maximum transfer of power from the feedline to the antenna. Equation 13 shows the relationship between return loss and VSWR [14].

Return loss $(\mathrm{dB})=-20 \log _{10}\left(\frac{V S W R-1}{V S W R+1}\right)(13)$

Figure 7 shows the variation of simulated and measured reflection coefficient $\left(\mathrm{S}_{11} / \mathrm{S}_{22}(\mathrm{~dB})\right)$ as the function of frequency. The proposed fractal array covers a simulated operational band from 4.395-10.184 GHz $(79.4 \%$ fractional bandwidth) and peak $\mathrm{S}_{11} / \mathrm{S}_{22}(\mathrm{~dB})$ of $-54.5 \mathrm{~dB}$ at $9.4 \mathrm{GHz}$ frequency. The measured results on a VNA show a frequency band from 4.6-10.45 GHz (port-1, $\mathrm{S}_{11}$ ) and 4.55-10.32 GHz (port-2, $\mathrm{S}_{22}$ ) with fractional bandwidths of $77.7 \% \mathrm{GHz}$ and $77.6 \%$ respectively. The simulated and measured $\mathrm{S}_{11} / \mathrm{S}_{22}(\mathrm{~dB})$ responses show an acceptable similitude of $95 \%$ match at the lower frequency band and a $97 \%$ match at the higher frequency band.

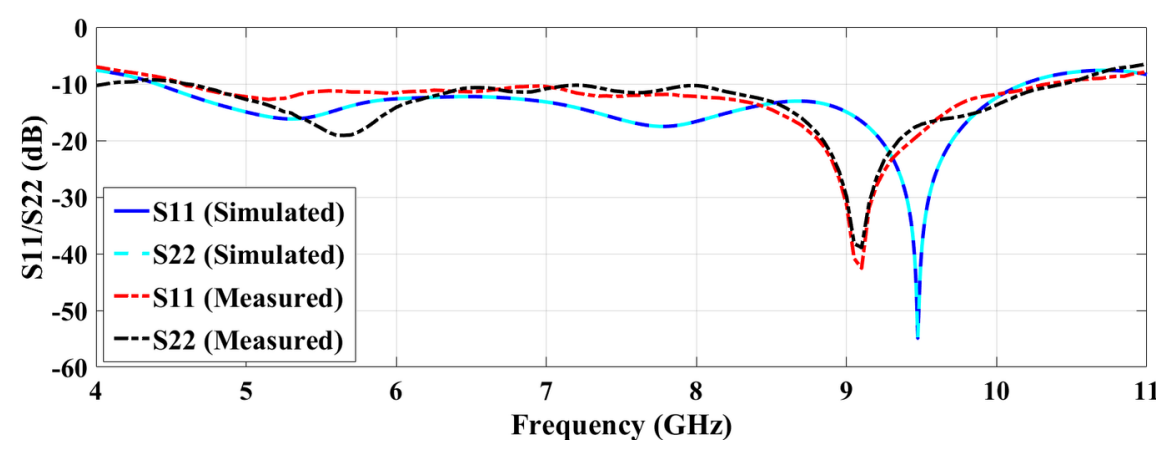

Figure 7 Comparative plot of simulated and measured reflection coefficient $\left(\mathrm{S}_{11} / \mathrm{S}_{22}\right)$

Figure 8 shows the variation of simulated and measured and transmission coefficient $\left(\mathrm{S}_{21} / \mathrm{S}_{12}\right)$ with respect to the frequency. Isolation is a positive quantity and can be calculated using Equation (14).

Isolation $=-10 \log _{10}\left|S_{21}\right|^{2}(14)$

A good port-to-port isolation $\left(\mathrm{S}_{21} / \mathrm{S}_{12}\right.$ [?] $-16.8 \mathrm{~dB}$ (simulated) and $\mathrm{S}_{21} / \mathrm{S}_{12}$ [?] $-19.3 \mathrm{~dB}$ (measured)) is achieved for the entire operational band from 4.395-10.184 GHz.

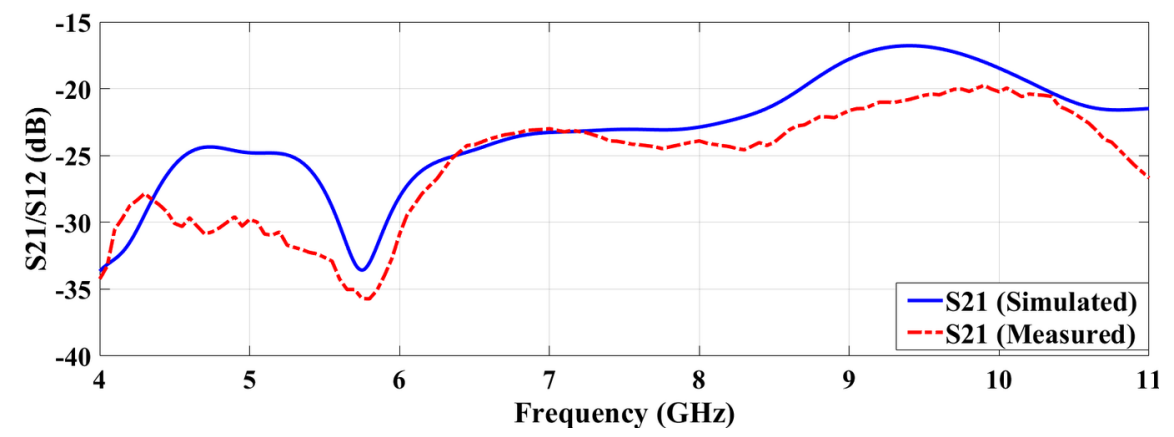

Figure 8 Simulated and measured transmission coefficient $\left(\mathrm{S}_{21} / \mathrm{S}_{12}\right)$ with respect to frequency

As shown in Figure 9, the proposed fractal array achieves a good match with the feedlines and power loss is minimal as simulated and measured VSWR values are less than 2 for the entire operational band. It validates the suitability of the proposed fractal MPA array for UWB-MIMO applications. 


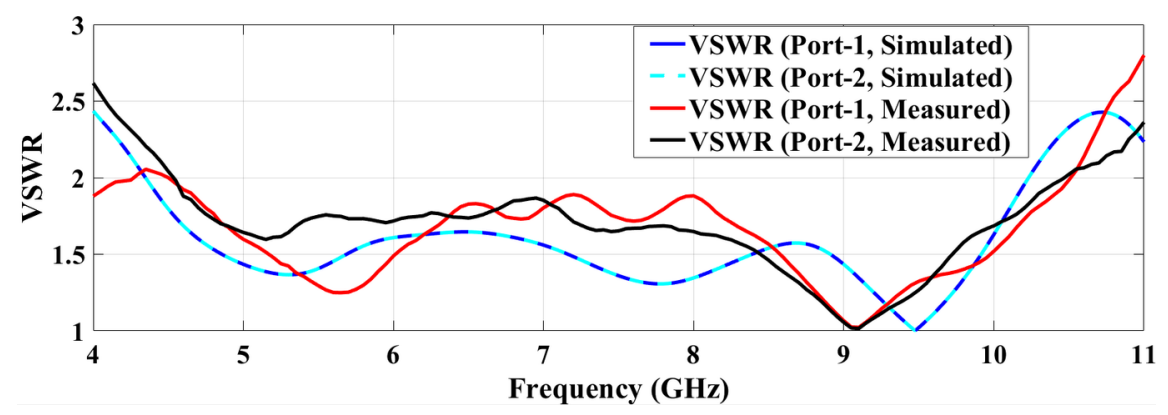

Figure 9 Variation of simulated and measured VSWR with respect to frequency

\section{BROADBAND GAIN AND RADIATION EFFICIENCY}

Figure 10 (a) shows the variation of antenna gain for the operational band from 4.395-10.184 GHz. Antenna gain quantifies the maximum distance that can be covered by the electromagnetic (EM) wave. The proposed fractal MPA array shows a maximum gain of $3.84 \mathrm{~dB}$ at $8.9 \mathrm{GHz}$ frequency (simulated) and $3.81 \mathrm{~dB}$ at 9.25 $\mathrm{GHz}$ frequency (measured) with an average simulated gain of [?] $1.2 \mathrm{~dB}$ (for both ports).

As shown in Figure 10 (b), the radiation efficiency $\left(\eta_{\mathrm{rad}}\right)$ is [?] $74 \%$ (simulated) throughout the UWB of operation. The proposed fractal array radiates with a maximum efficiency of $88.8 \%$ at $6.2 \mathrm{GHz}$ frequency.

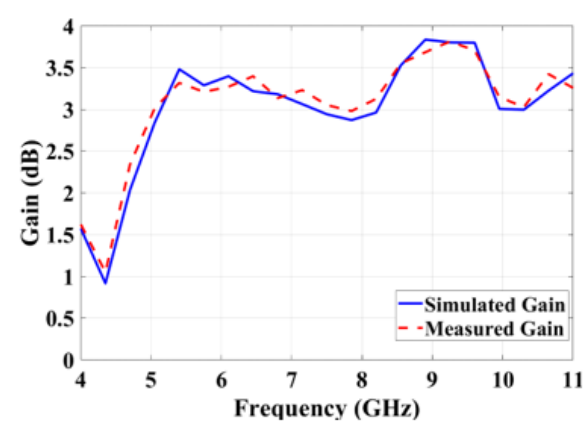

(a)

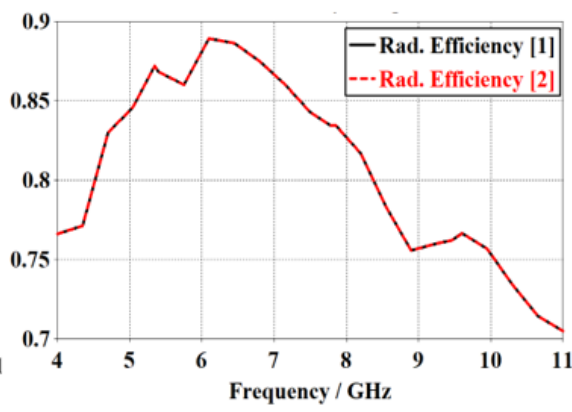

(b)

Figure 10 Variation of (a) gain (b) radiation efficiency with respect to the frequency

Figure 11 (a-c) shows the far-field radiation patterns (simulated) of the proposed fractal array at three resonances of $5.35 \mathrm{GHz}, 7.78 \mathrm{GHz}$ and $9.47 \mathrm{GHz}$ for excited port-1 and port-2. For activated port-1 and port-2 terminated, gain of $3.42 \mathrm{~dB}$ (at $5.35 \mathrm{GHz}), 2.88 \mathrm{~dB}$ (at $7.78 \mathrm{GHz}$ ) and $3.88 \mathrm{~dB}($ at $9.47 \mathrm{GHz})$ is achieved. Due to the mirror image layout of the antenna elements, port-2 shows the same gain performance with complementary far-field patterns at all three resonances. As a result, the radiating elements of the proposed array provide good diversity performance which validates its suitability for wireless applications supported by unlicensed UWB of operation. 


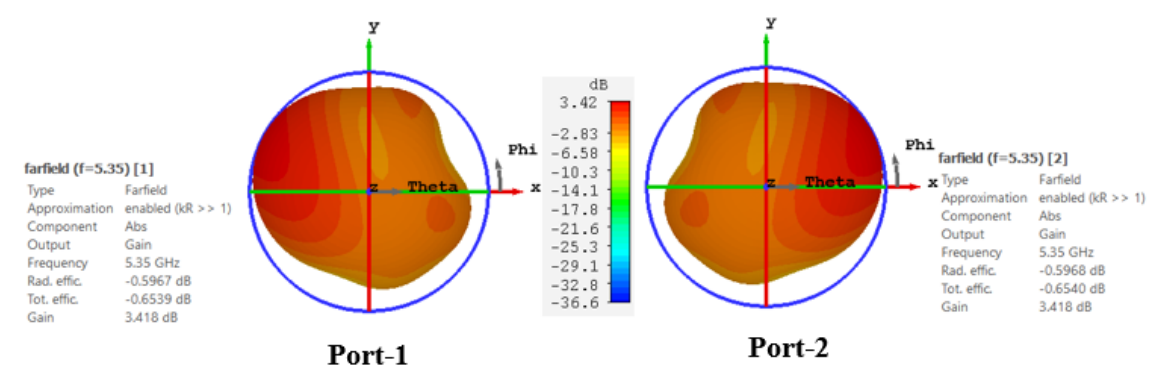

(a)

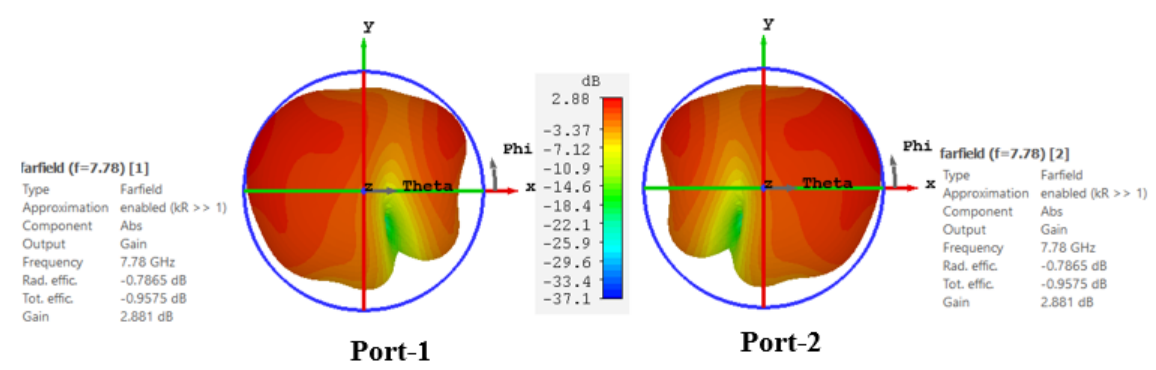

(b)

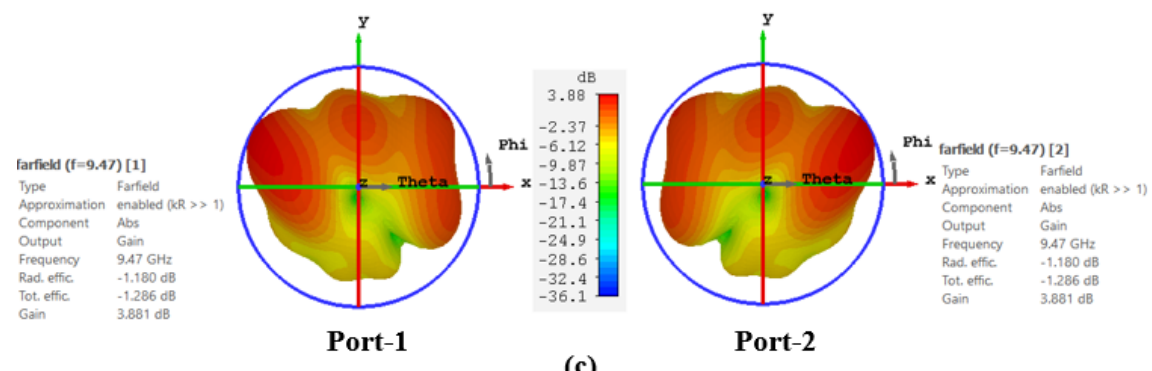

(c)

Figure $113 \mathrm{D}$ radiation pattern of the proposed fractal MPA array at (a) $5.35 \mathrm{GHz}$ (b) $7.78 \mathrm{GHz}$ (c) 9.47 $\mathrm{GHz}$

\section{SURFACE CURRENT DISTRIBUTION}

To determine the influence of mutual coupling between the two array elements, Figure 12 (a-f) shows the current distribution at three resonant frequencies of $5.35 \mathrm{GHz}, 7.78 \mathrm{GHz}$ and $9.47 \mathrm{GHz}$. As shown in Figure 12 (a-f), the funnel-shaped stub and slotted ground plane decouples the energy from the fractal radiators and are mainly responsible for improving the isolation level between the two ports. This is also validated by the parametric analysis of the ground plane presented in Section 2. For port-1 excited by simulated $1 \mathrm{~W}$ of power at the feed point (port-2 deactivated by $50 \Omega$ load), the decoupling structure (inserted in the ground plane) allows a very small amount of current to flow through the non-activated port-2 for all three resonances. For activated port-2 and port-1 terminated, a similar reduction of coupling current is observed. Hence, the proposed fractal MPA array exhibits good isolation performance throughout the UWB of operation. 


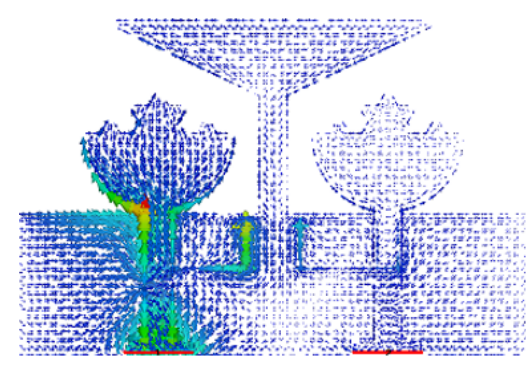

(a)

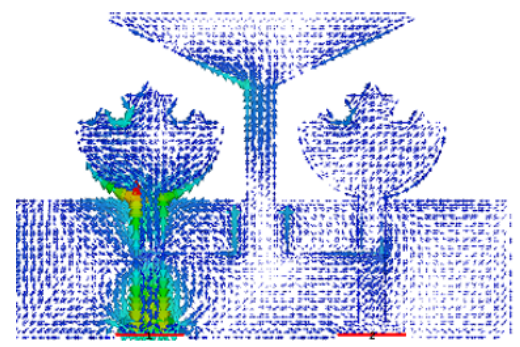

(c)

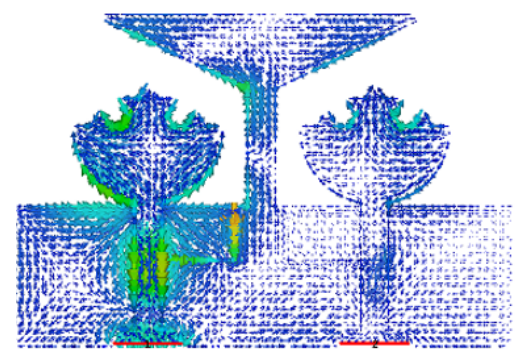

(e)

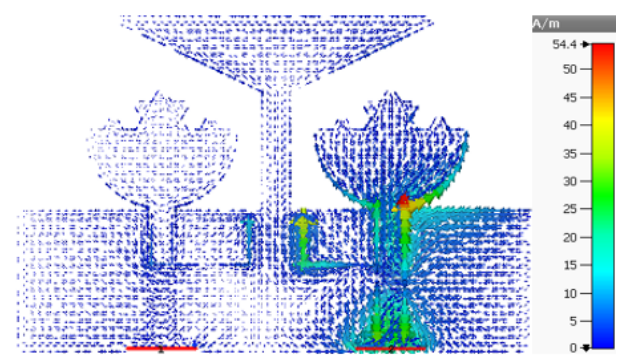

(b)

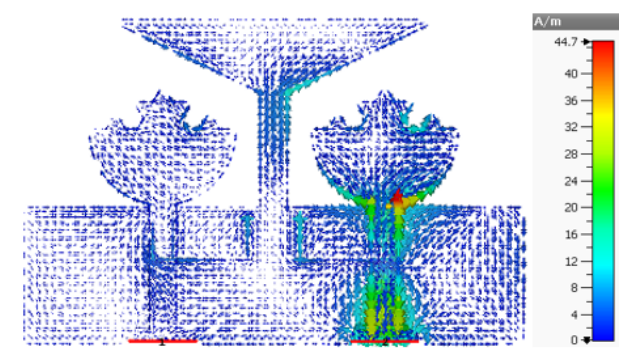

(d)

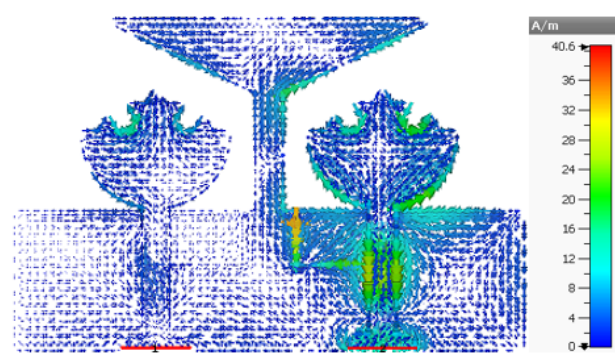

(f)

Figure 12 Surface current distributions for the proposed fractal MPA array at (a) $5.35 \mathrm{GHz}$ (Port-1) (b) $5.35 \mathrm{GHz}$ (Port-2) (c) $7.78 \mathrm{GHz}$ (Port-1) (d) $7.78 \mathrm{GHz}$ (Port-2) (e) $9.47 \mathrm{GHz}$ (Port-1) (f) $9.47 \mathrm{GHz}$ (Port-2)

\section{DIVERSITY CHARACTERISTICS}

To characterize the feasibility of the proposed dual-port fractal array for UWB-MIMO systems, various diversity performance metrics such as ECC, DG, MEG, CCL and TARC are analyzed in this section.

For a two-element MPA, ECC is a crucial diversity parameter to quantify the amount of correlation between the signals received from adjacent communication channels. DG is defined as the figure of merit to determine the potency of the applied diversity scheme. For any practical MIMO application, the acceptable limit of ECC and DG to receive uncorrelated signals is less than 0.05 and greater than 9.95 respectively. ECC $(\rho)$ can be computed from S-parameters using Equation (15) and Equation (16) defines the relationship between ECC and DG [8].

$\rho=\frac{\left|S_{11}^{*} S_{12}+S_{21}^{*} S_{22}\right|^{2}}{\left(\left(1-\left(\left|S_{11}\right|^{2}+\left|S_{21}\right|^{2}\right)\right)\left(1-\left(\left|S_{22}\right|^{2}+\left|S_{12}\right|^{2}\right)\right)\right)}(15)$

$D G=10 \sqrt{1-|\rho|^{2}}$ 
Figure $13(\mathrm{a}, \mathrm{b})$ shows the variation of ECC and DG with respect to frequency for the proposed fractal array. It shows a low level of ECC ([?] 0.0021 (simulated), [?] 0.0023 (measured)) and a high degree of DG ([?] 9.989 (simulated), [?] 9.988 (measured)) for a complete operational range which affirms a good diversity performance of the proposed MPA array.

CCL is the third significant diversity parameter that determines the degree of deterioration of array performance as a result of the correlation in the MIMO channel. For high SNR, CCL can be computed from S-parameters using Equation (17) [6].

$\mathrm{CCL}=-\log _{2} \operatorname{det}\left(\Psi^{R}\right)$

where $\Psi^{\mathrm{R}}$ is a $2 \times 2$ correlation matrix and given by Equation (18).

$\Psi^{R}=$

)$\neq$

$\left(\begin{array}{cc}1-\left(\left|S_{11}\right|^{2}+\left|S_{12}\right|^{2}\right. & a m p ;-\left(S_{11}^{*} S_{12}+S_{21}^{*} S_{12}\right) \\ -\left(S_{22}^{*} S_{21}+S_{12}^{*} S_{21}\right) & a m p ; 1-\left(\left|S_{22}\right|^{2}+\left|S_{21}\right|^{2}\right)\end{array}\right)$

Figure 13 (c) shows that the value of CCL is [?] $0.4 \mathrm{bits} / \mathrm{s} / \mathrm{Hz}$ (simulated and measured) for the entire operational range which indicates high port-to-port isolation between the array elements.

MEG is another important diversity metric as it determines the antenna gain performance by taking into account the real fading scenario. Equations $(19,20)$ are used for calculating MEG (for both the ports) by considering the radiation efficiencies at the two ports. For good diversity performance, the difference in MEG for two ports should be less than $3 \mathrm{~dB}$ (Equation (21)) [6].

$\mathrm{MEG}_{\text {port }-1}=0.5 \eta_{\text {rad, }}$ port-1 $=0.5\left(1-\left|S_{11}\right|^{2}-\left|S_{12}\right|^{2}\right)(19)$

$\mathrm{MEG}_{\text {port }-2}=0.5 \eta_{\text {rad }}$, port $-2=0.5\left(1-\left|S_{21}\right|^{2}-\left|S_{22}\right|^{2}\right)(20)$

$\left|\mathrm{MEG}_{\text {port-1 }}-\mathrm{MEG}_{\text {port-2 }}\right|<3 d B(21)$

As shown in Figure 13 (d), a maximum MEG of $-3.018 \mathrm{~dB}$ (simulated) at $5.88 \mathrm{GHz}$ frequency and $-3.011 \mathrm{~dB}$ (measured) at $6.2 \mathrm{GHz}$ frequency is observed with an overall MEG [?] -3.7 dB (simulated) and [?] -3.85 dB (measured). The difference between the MEG for two ports is $0 \mathrm{~dB}$ (simulated) and $0.69 \mathrm{~dB}$ (measured). This makes the proposed fractal array feasible for MIMO employment in UWB radio systems.

TARC is also an essential diversity metric to properly identify the antenna array performance in terms of bandwidth and efficiency. TARC consists of a single curve, obtained by concentrating all the details of scattering parameters for a multi-element antenna array. Mathematically, TARC is calculated using Equation (22-27) [15].

$\Gamma_{a}^{t}=\sqrt{\frac{\text { reflected power }}{\text { incident power }}}=\sqrt{\frac{\sum_{i=1}^{N}\left|b_{i}\right|^{2}}{\sum_{i=1}^{N}\left|a_{i}\right|^{2}}}(22)$

$[b]=[S] \cdot[a](23)$

where $\mathrm{b}$ is the reflected signal vector, $\mathrm{a}$ is the incident signal vector and $\mathrm{S}$ is scattering matrix. Assuming multipath wave propagation and gaussian MIMO channels, the reflected signal for two-port antenna network is given by Equation (24-26).

$$
\begin{aligned}
& {\left[\begin{array}{l}
b_{1} \\
b_{2}
\end{array}\right]=} \\
& {\left[\begin{array}{ll}
S_{11} & a m p ; S_{12} \\
S_{21} & a m p ; S_{22}
\end{array}\right]}
\end{aligned}
$$


$b_{1}=S_{11} a_{1}+S_{12} a_{2}=a_{0} S_{11} e^{i \theta_{1}}+a_{0} S_{12} e^{i \theta_{2}}=a_{1}\left(S_{11}+e^{\imath \vartheta} S_{12}\right)$

$b_{2}=S_{21} a_{1}+S_{22} a_{2}=a_{0} S_{21} e^{i \theta_{1}}+a_{0} S_{22} e^{i \theta_{2}}=a_{1}\left(S_{21}+e^{\imath \vartheta} S_{22}\right)(26)$

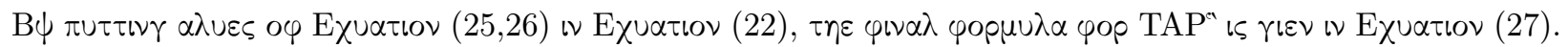

$$
\Gamma_{a}^{t}=\frac{\sqrt{\left|\left(S_{11}+S_{12} e^{\vartheta \vartheta}\right)\right|^{2}+\left|\left(S_{11}+S_{12} e^{\vartheta \vartheta}\right)\right|^{2}}}{}
$$

$\varepsilon \vee \gamma \lambda เ \sigma \eta \sqrt{2}(27)$

$\omega \eta \varepsilon p \varepsilon$ ' $\vartheta$ ' is the input feed phase difference.

As shown in Figure 13 (e, f), TARC (dB) curves are plotted for variation in ' $\vartheta$ ' (0@, 30@, 60@, 90@, 120@, 150@,180@) with respect to the frequency. The simulated and measured TARC values less than $-10 \mathrm{~dB}$ and $-8.9 \mathrm{~dB}$ respectively are observed for all variations of ' $\theta$ '. The simulated and measured TARC resonance curves (at a feed phase difference of 30@) show a good resemblance with the simulated and measured $\mathrm{S}_{11} / \mathrm{S}_{22}$ $(\mathrm{dB})$ curves respectively. A slight deviation in resonant characteristics is observed due to the presence of some cross-coupling between the actively radiating elements of the array. Table 2 shows that the proposed fractal array exhibits improved performance in terms of compactness, large bandwidth and acceptable diversity characteristics as compared to the previously published $2 \times 2$ fractal antenna arrays. 


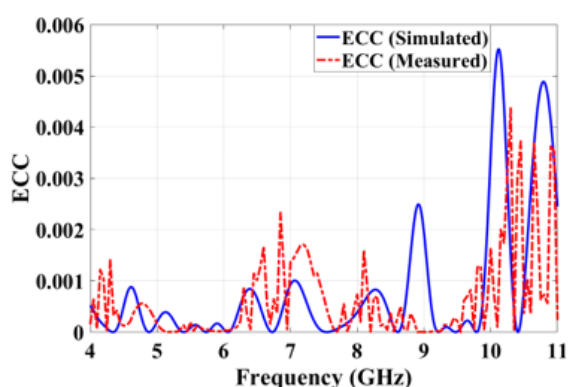

(a)

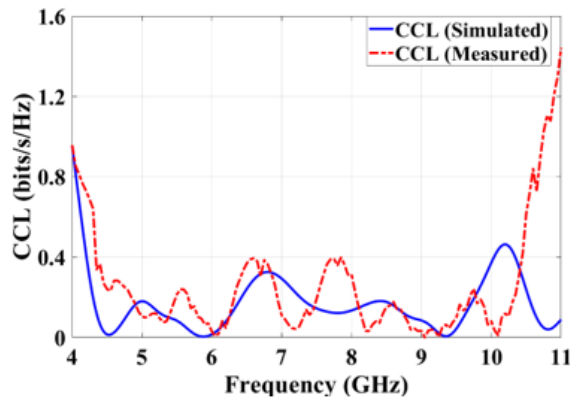

(c)

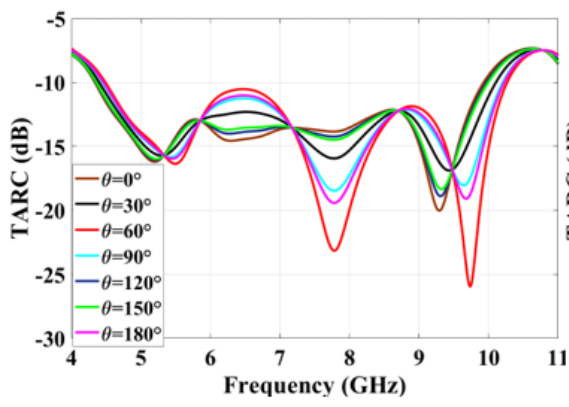

(e)

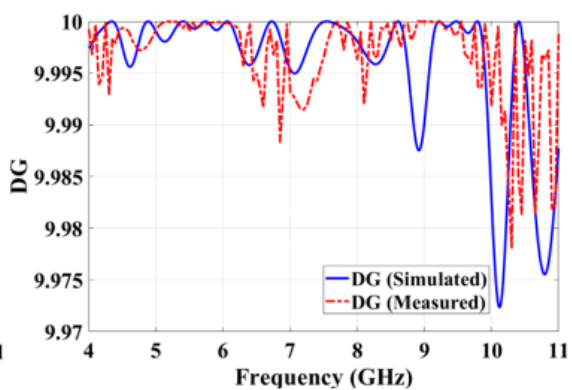

(b)

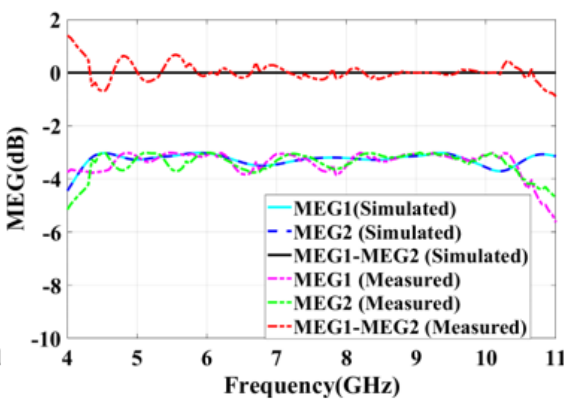

(d)

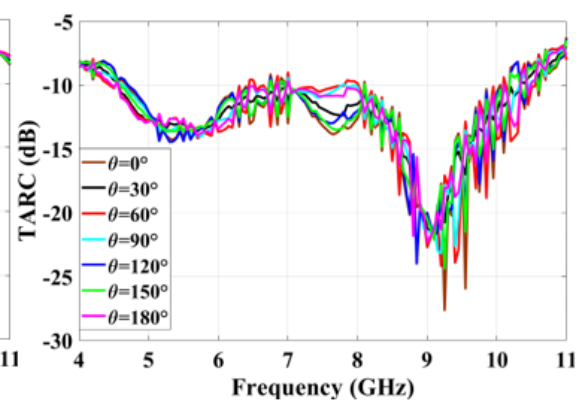

(f)

Figure 13 Variation of (a) ECC (b) DG (c) CCL (d) MEG (e) TARC (dB) (Simulated) (f) TARC (dB) (Measured) with respect to the frequency

Table 2 Comparison of proposed fractal MPA array with the previously reported $2 \times 2$ multiband /wideband MIMO antennas

\begin{tabular}{|c|c|c|c|c|c|c|}
\hline Ref. & $\begin{array}{l}\text { Substrate } \\
\text { Dimensions } \\
\left(\mathrm{mm}^{2}\right)\end{array}$ & $\begin{array}{l}\text { Fractal } \\
\text { geometry }\end{array}$ & $\begin{array}{l}\text { Frequency } \\
\text { range }(\mathrm{GHz})\end{array}$ & ECC & MEG (dB) & $\begin{array}{l}\text { CCL } \\
(\text { bits } / \mathrm{s} / \mathrm{Hz})\end{array}$ \\
\hline [8] & $136 \times 136$ & $\begin{array}{l}\text { Complementary } \\
\text { Sierpinski } \\
\text { Gasket }\end{array}$ & $4.74-5.15$ & [?] 0.06 & - & - \\
\hline$[10]$ & $\begin{array}{l}121.8 \times \\
68.45\end{array}$ & $\begin{array}{l}\text { Hilbert } \\
\text { curve }\end{array}$ & $\begin{array}{l}2.4-2.489 \\
5-6\end{array}$ & {$[?] \quad 0.1$} & {$[?]-4$} & - \\
\hline [11] & $100 \times 50$ & $\begin{array}{l}\text { Minkowski } \\
\text { and Koch } \\
\text { curve }\end{array}$ & $\begin{array}{l}1.65-1.9 \\
2.68-6.45\end{array}$ & [?] 0.025 & - & [?] 0.3 \\
\hline
\end{tabular}




\begin{tabular}{|c|c|c|c|c|c|c|}
\hline Ref. & $\begin{array}{l}\text { Substrate } \\
\text { Dimensions } \\
\left(\mathrm{mm}^{2}\right)\end{array}$ & $\begin{array}{l}\text { Fractal } \\
\text { geometry }\end{array}$ & $\begin{array}{l}\text { Frequency } \\
\text { range }(\mathrm{GHz})\end{array}$ & ECC & MEG (dB) & $\begin{array}{l}\text { CCL } \\
(\text { bits/s/Hz) }\end{array}$ \\
\hline$[16]$ & $40 \times 82$ & Koch curve & $\begin{array}{l}0.9-1, \\
1.73-1.79, \\
2.6-2.8, \\
3.6-3.7, \\
4.2-4.4, \\
5.5-5.6, \\
5.9-6.1\end{array}$ & [?] 0.05 & - & {$[?] 0.5$} \\
\hline$[17]$ & $51 \times 50$ & $\begin{array}{l}\text { Dragon and } \\
\text { Koch curve }\end{array}$ & $\begin{array}{l}0.401-0.468, \\
2.39-2.48, \\
3.92-4, \\
4.58-4.77 \\
5.46-5.98\end{array}$ & [?] 0.01 & - & [?] 0.4 \\
\hline$[18]$ & $40 \times 50$ & $\begin{array}{l}\text { Sunflower } \\
\text { fractal }\end{array}$ & $2-2.9,5-10$ & [?] 0.05 & - & [?] 0.4 \\
\hline $\begin{array}{l}\text { Proposed } \\
\text { Fractal } \\
\text { array }\end{array}$ & $30.5 \times 47$ & Koch curve & $4.395-10.184$ & {$[?] 0.0021$} & {$[?]-3.7$} & [?] 0.4 \\
\hline
\end{tabular}

\section{CONCLUSION}

A compact dual-port microstrip line fed MPA array with Koch curve fractals for portable UWB-MIMO systems is proposed in this article. The proposed fractal array occupies an overall area of $1433.5 \mathrm{~mm}^{2}(30.5$ $\mathrm{mm} \times 47 \mathrm{~mm})$. The upper substrate layer consists of two semi-circular patches joined with Koch curve fractals (optimized up to $2^{\text {nd }}$ order of iteration) and the lower substrate layer consists of a reduced ground plane with slots and a funnel-shaped decoupling structure. The radiating elements in the array are kept at a distance of $\lambda / 2$ to mitigate the effect of mutual coupling between the ports. The simulated results show a wide frequency band of 4.395-10.184 GHz with a fractional bandwidth of $79.4 \%$ (at a center frequency of $5.789 \mathrm{GHz}$ ), the peak radiation efficiency of $88.8 \%$ (at $6.2 \mathrm{GHz}$ frequency) and a high isolation level $\left(\mathrm{S}_{21} / \mathrm{S}_{12}\right.$ [?] -16.8 dB). The measured S-parameter results cover the frequency band from 4.6-10.45 GHz (port-1, $\mathrm{S}_{11}$ ) and 4.55-10.32 GHz (port-2, $\mathrm{S}_{22}$ ) with fractional bandwidths of $77.7 \% \mathrm{GHz}$ and $77.6 \%$ respectively and $\mathrm{S}_{21} / \mathrm{S}_{12}$ [?] -19.3 dB. The proposed fractal array exhibits low ECC ([?] 0.0021 (simulated), [?] 0.0023 (measured)), high DG ([?] 9.989 (simulated), [?] 9.988 (measured)), high MEG ([?] -3.7 dB (simulated) and [?] -3.85 dB (measured)), low CCL ([?] $0.4 \mathrm{bits} / \mathrm{s} / \mathrm{Hz}$ (simulated, measured)) and acceptable TARC (-10 dB (simulated), $-8.9 \mathrm{~dB}$ (measured)) values which makes it an appropriate choice for portable and high data rate UWB communication systems.

\section{ACKNOWLEDGMENT}

We would like to thank the Thapar Institute of Engineering and Technology, Patiala for providing the necessary infrastructure and facilities to support this research work.

\section{CONFLICT OF INTEREST}

The author declares no potential conflict of interest.

\section{REFERENCES}

1. Goldsmith, Wireless Communications. Cambridge: Cambridge University Press, 2005.

2. H. Zhao, F. Zhang, C. Wang and X. Zhang, "A universal methodology for designing a UWB diversity antenna," Journal of Electromagnetic Waves and Applications . vol. 28, no. 10, pp. 1221-1235, 2014. DOI: https://doi.org/10.1080/09205071.2014.911667. 
3. S. Chouhan, D.K. Panda, M. Gupta and S. Singhal, "Multiport MIMO antennas with mutual coupling reduction techniques for modern wireless transreceive operations: A review," International Journal RF and Microwave Computer-Aided Engineering , vol. 28, e21189, 2018, DOI: https://doi.org/10.1002/mmce.21189.

4. S.P. Biswal and S. Das, "A low-profile dual port UWB-MIMO/diversity antenna with band rejection ability," International Journal RF and Microwave Computer-Aided Engineering . vol. 28, e21159, 2018, DOI: https://doi.org/10.1002/mmce.21159.

5. C.A. Balanis, Antenna Theory: Analysis and Design, New York: John Wiley \& Sons, 2005.

6. R. Gurjar, D.K. Upadhyay, B.K. Kanaujia and K. Sharma. "A novel compact self-similar fractal UWB MIMO antenna," International Journal RF and Microwave Computer-Aided Engineering . vol. 29, e21632, 2019, DOI: https://doi.org/10.1002/mmce.21632.

7. A. Arya, M.V. Kartikeyan and A. Patnaik, "Defected ground structure in the perspective of microstrip antennas: A review," Frequenz . vol. 64, pp. 79-84, 2010. DOI: 10.1515/FREQ.2010.64.5-6.79.

8. A. Kaur and S. Gupta, "A complementary sierpinski gasket fractal antenna array for wireless MIMO portable devices," Microwave and Optical Technology Letters. vol. 61, pp. 436-442, 2019. DOI: https://doi.org/10.1002/mop.31584.

9. S.V. Khobragade, S.L. Nalbalwar, A.B. Nandgaonkar and A.E. Wagh, "Design of Asymmetrical Antenna using slotted mirror image ground aperture coupling for multiband applications," IETE Journal of Research , 2019. DOI: 10.1080/03772063.2019.1599738.

10. A. Peristerianos, A. Theopoulos, A.G. Koutinos, T. Kaifas and K. Siakavara, "Dual-Band Fractal Semi-Printed Element Antenna Arrays for MIMO Applications," IEEE Antennas and Wireless Propagation Letters, vol. 15, pp. 730-733, 2016, DOI: https://doi.org/10.1109/LAWP.2015.2470681.

11. Y.K. Choukiker, S.K. Sharma and S.K. Behera, "Hybrid Fractal Shape Planar Monopole Antenna Covering Multiband Wireless Communications with MIMO Implementation for Handheld Mobile Devices," IEEE Transactions on Antennas and Propagation, vol. 62, no. 3, pp. 1483-1488, 2014. DOI: https://doi.org/10.1109/TAP.2013.2295213.

12. M.L. Meena and A. Gupta, "Design Analysis of a Semi-Circular Floral Shaped Directional UWB Antenna Integrated with Wireless Multiband Applications", Progress In Electromagnetics Research C, vol. 90, pp.155-167, 2019, DOI: 10.2528/PIERC18110301.

13. M.G. Siddiqui, A.K. Saroj, Devesh and J.A. Ansari, "Multi-Band Fractaled Triangular Microstrip Antenna for Wireless Applications", Progress In Electromagnetics Research M , vol. 65, pp. 51-60, 2018. DOI: 10.2528/PIERM18011027.

14. A. Kaur and A. Kaur, "An Extended Semi-circular Microstrip Patch Antenna with DGS for UWB Applications," Journal of Microwave Engineering and Technology, vol. 4, pp. 13-18, 2017.

15. S.H. Chae, S. Oh and S. Park, "Analysis of Mutual Coupling, Correlations, and TARC in WiBro MIMO Array Antenna," IEEE Antennas and Wireless Propagation Letters , vol. 6, pp. 122-125, 2007. DOI: https://doi.org/10.1109/LAWP.2007.893109.

16. S. Rajkumar, N.V. Sivaraman, S. Murali and K.T. Selvan, "Heptaband swastik arm antenna for MIMO applications," IET Microwaves, Antennas \& Propagation, vol. 11, no. 9, pp. 1255-1261, 2017. DOI: https://doi.org/10.1049/iet-map.2016.1098.

17. S. Rajkumar, N. Srinivasan, A. Natesan and K.T. Selvan, "A penta-band hybrid fractal MIMO antenna for ISM applications," International Journal RF and Microwave Computer-Aided Engineering, vol. 28, 2018. DOI: https://doi.org/10.1002/mmce.21185.

18. A.T. Abed, "Novel sunflower MIMO fractal antenna with low mutual coupling and dual wide operating bands," International Journal of Microwave and Wireless Technologies, pp. 1-9, 2019. DOI:10.1017/S1759078719001375. 


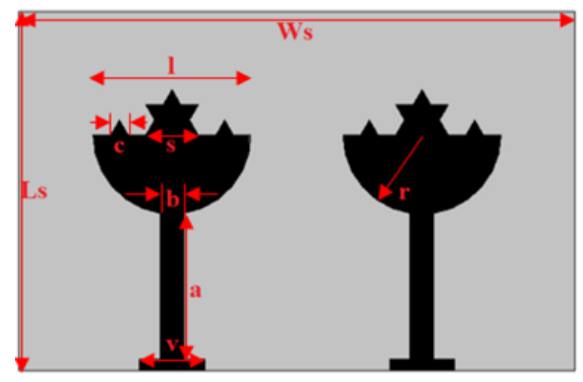

(a)

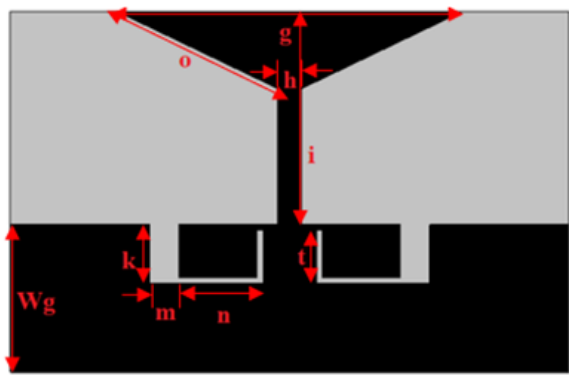

(b)

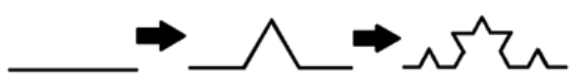

(c)

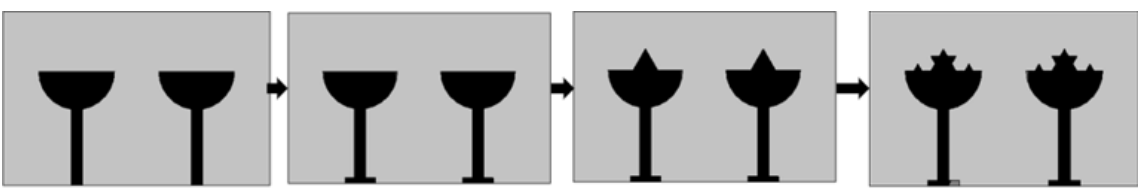

(a)

(b)

(c)

(d)
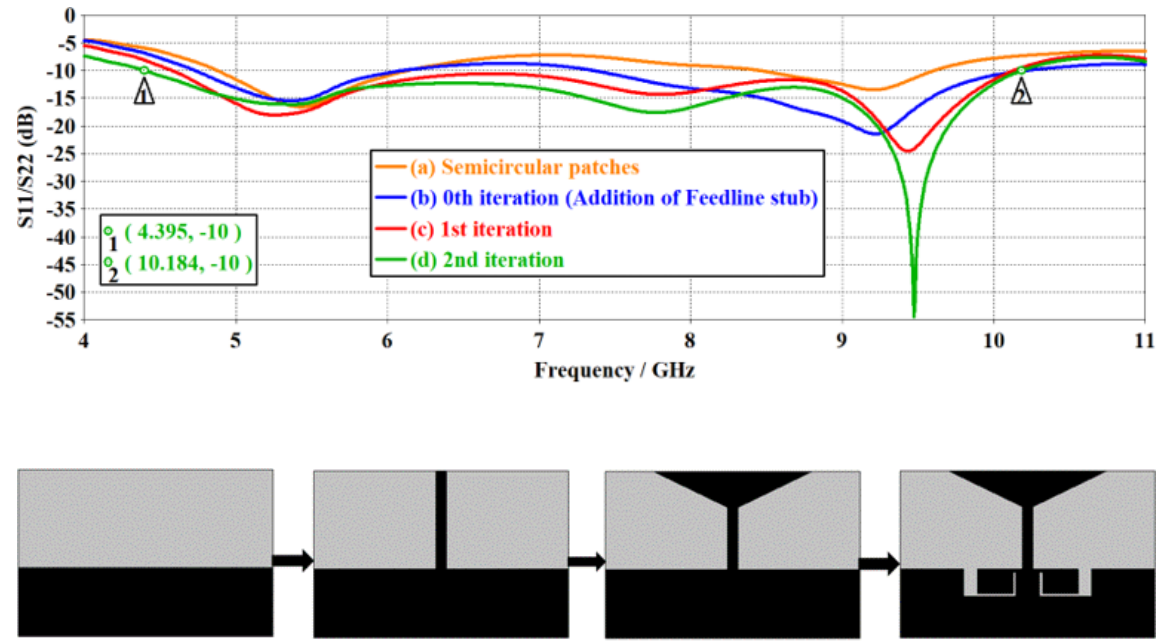

(a)

(b)

(c)

(d)

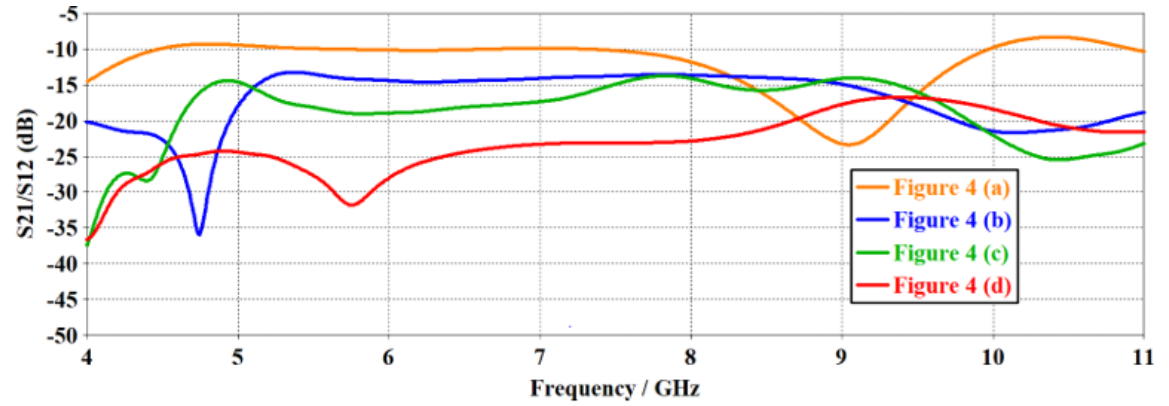




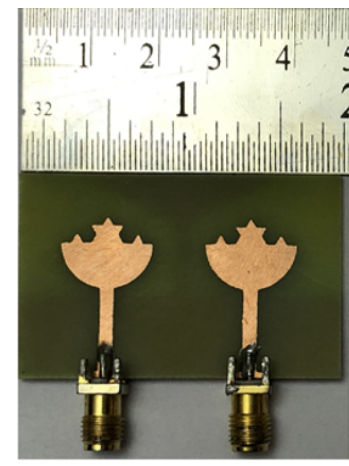

(a)

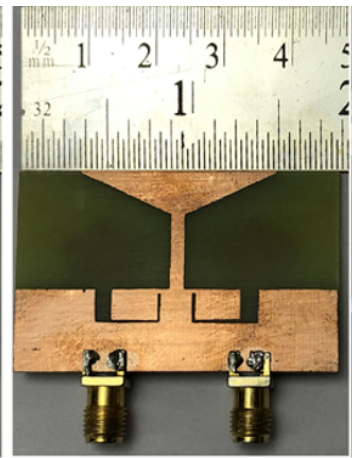

(b)

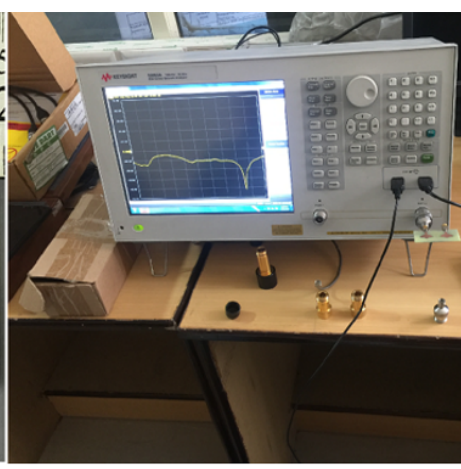

(c)
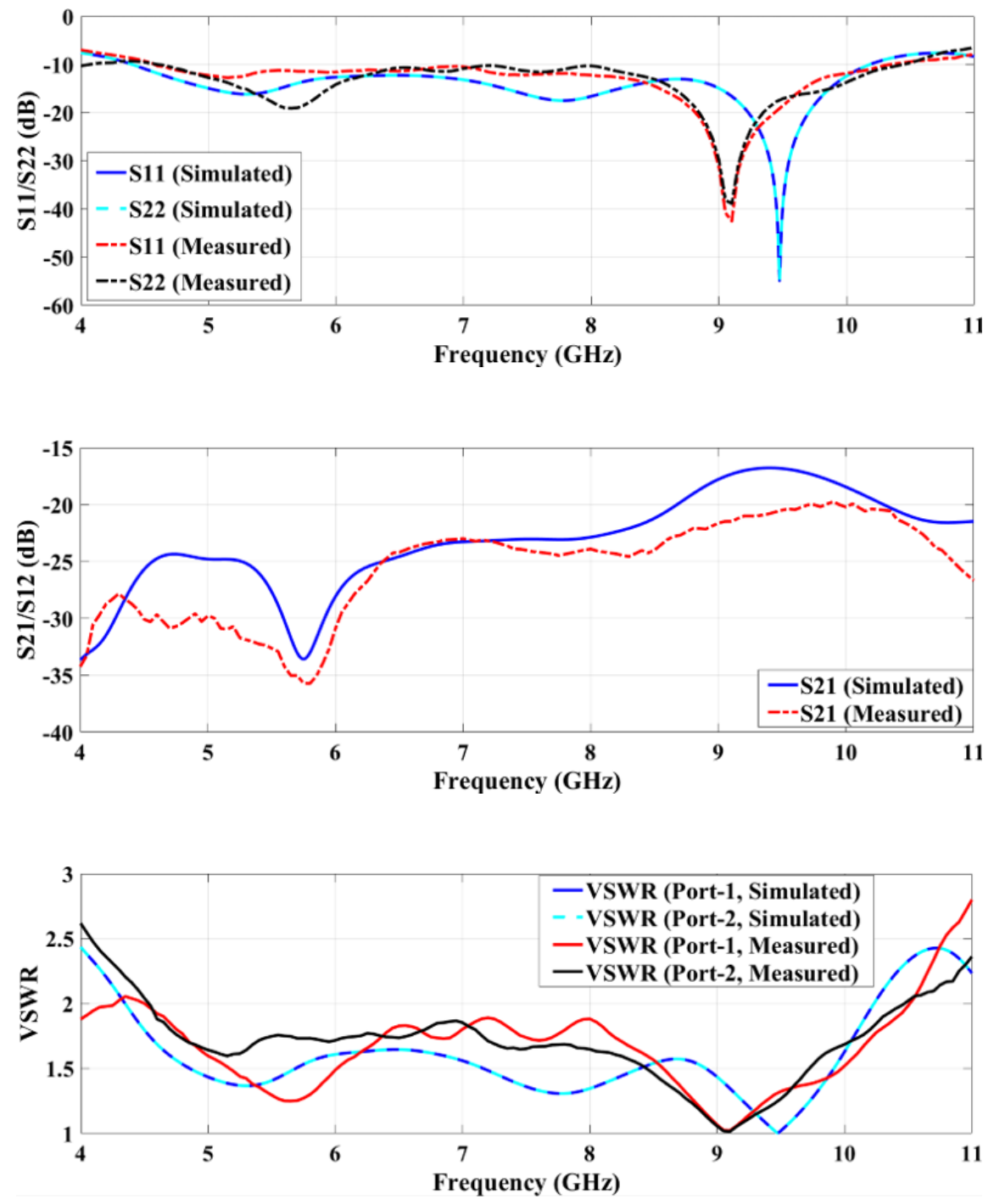


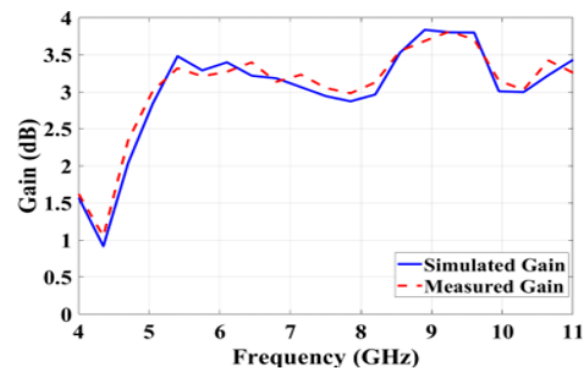

(a)

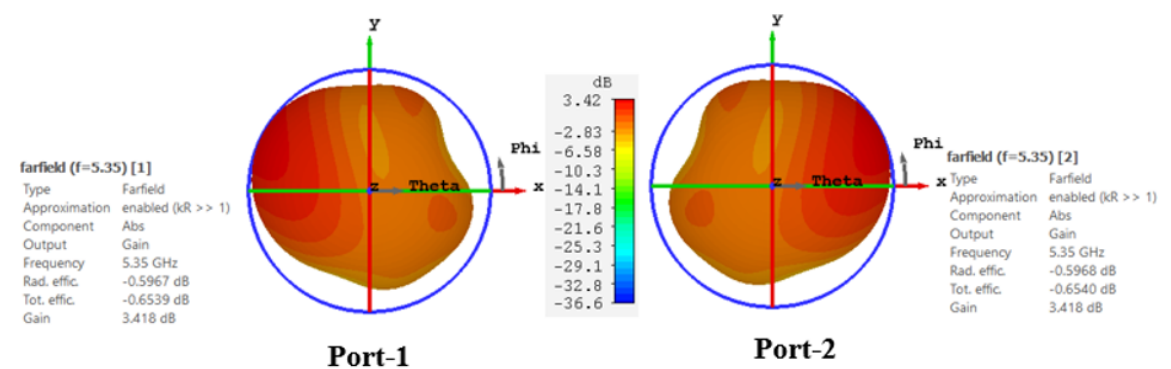

(a)
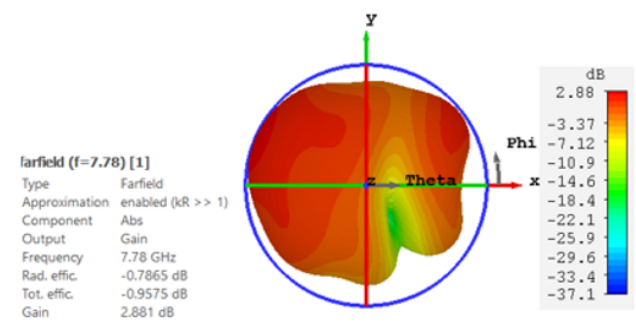

Port-1

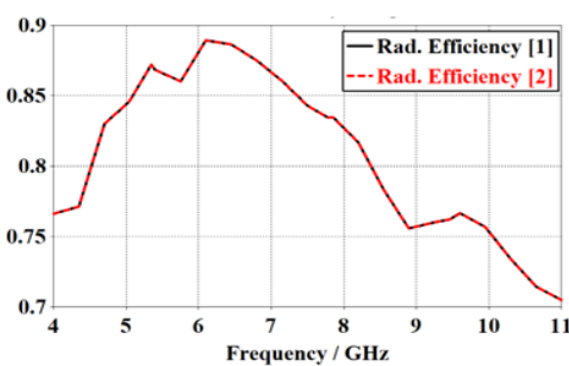

(b)

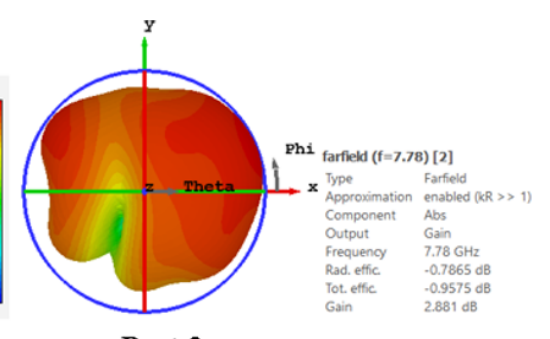

(b)

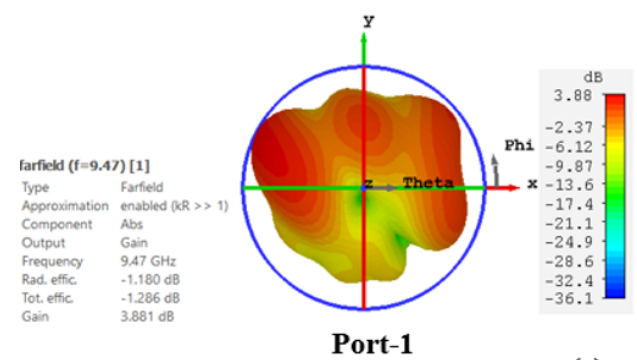

(c)

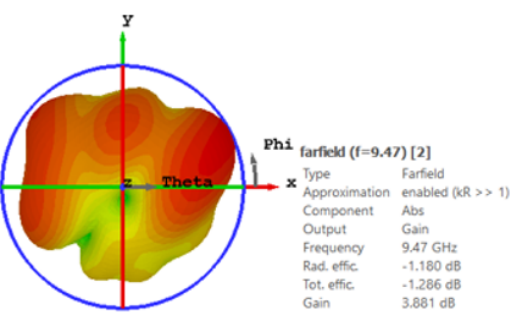

Port-2 


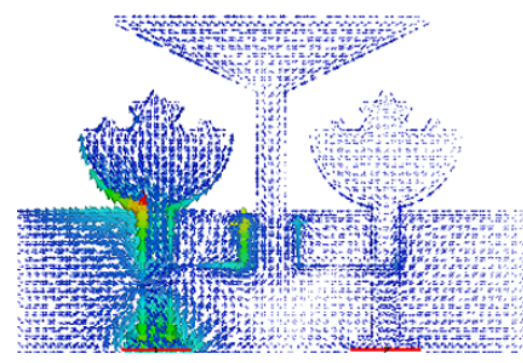

(a)

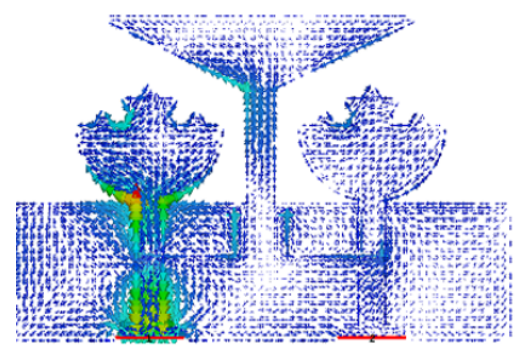

(c)

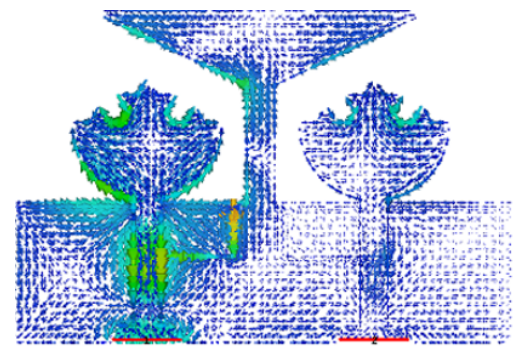

(e)

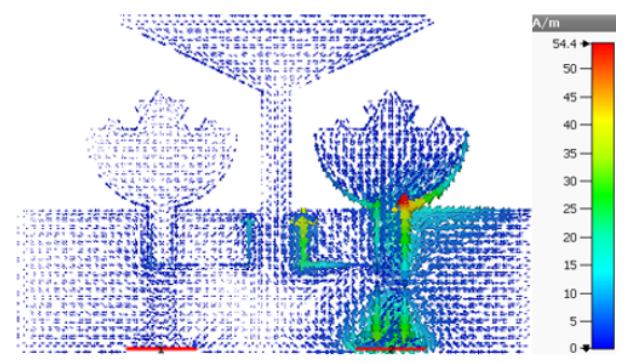

(b)

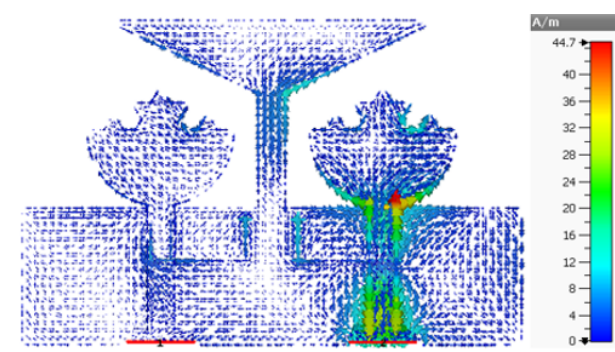

(d)

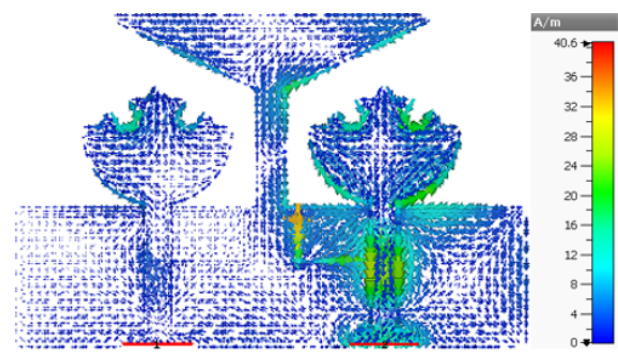

(f) 


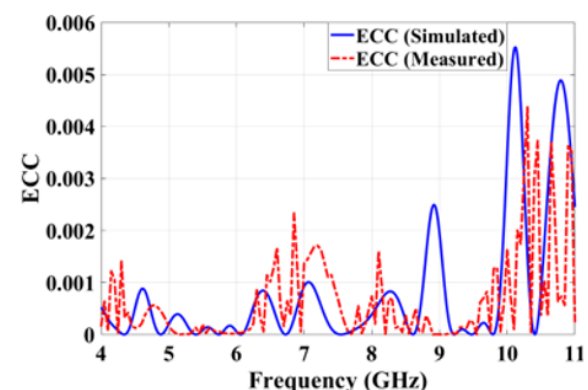

(a)

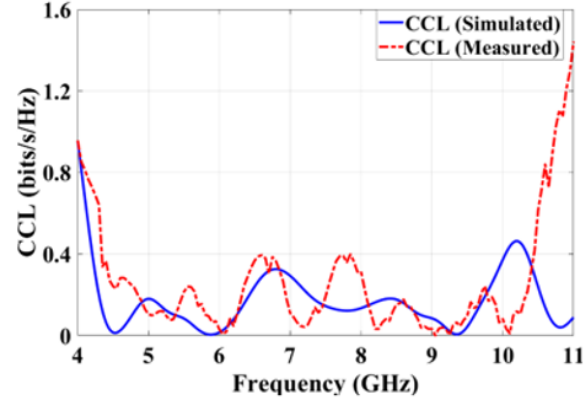

(c)

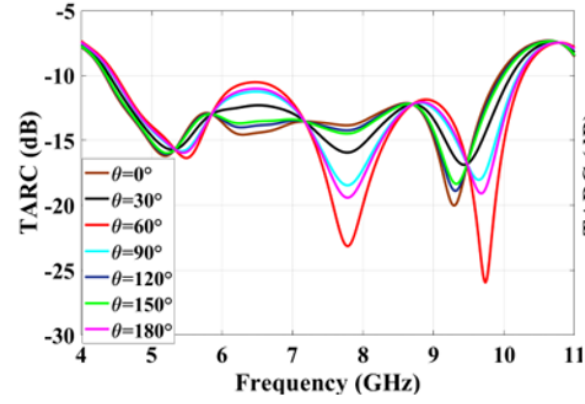

(e)

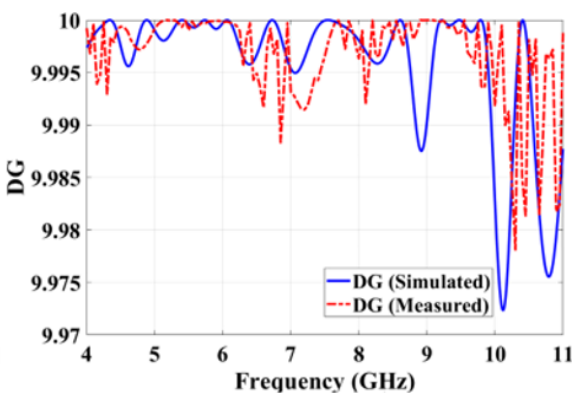

(b)

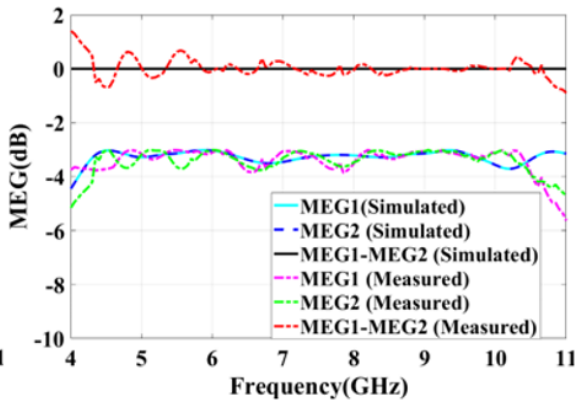

(d)

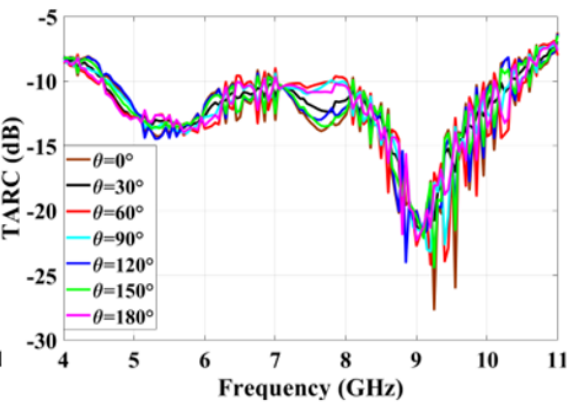

(f) 